
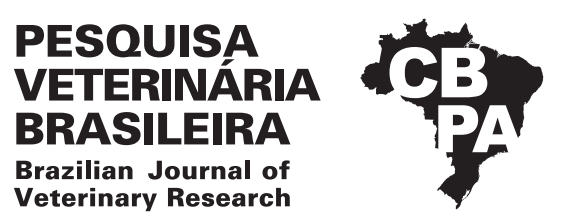

Pesq. Vet. Bras. 38(7):1317-1326, julho 2018 DOI: $10.1590 / 1678-5150-P V B-4174$

Artigo Original

ISSN 0100-736X (Print)

ISSN 1678-5150 (Online)

\title{
Ocorrência de anticorpos anti-Toxoplasma gondii e anti-Neospora caninum em ovinos com distúrbios reprodutivos e fatores de risco $^{1}$
}

\author{
Huber Rizzo ${ }^{2 *}$, Eliana M. C. Villalobos ${ }^{3}$, Enoch B.S. Meira Júnior ${ }^{4}$, \\ Eduardo C. Marques ${ }^{4}$, Fidel Beraldi ${ }^{5}$ e Lilian Gregory ${ }^{3}$
}

\begin{abstract}
Rizzo H., Villalobos E.M.C., Meira Júnior E.B.S., Marques E.C., Beraldi F. \& Gregory L. 2018. [Occurrence of antibodies anti-Toxoplasma gondii and anti-Neospora caninum in sheep with history of reproductive disorders and risk factors.] Ocorrência de anticorpos anti-Toxoplasma gondii e anti-Neospora caninum em ovinos com distúrbios reprodutivos e fatores de risco. Pesquisa Veterinária Brasileira 38(7):1317-1326. Setor de Clínica, Departamento de Medicina Veterinária, Universidade Federal Rural de Pernambuco, Rua Dom Manoel Medeiros s/n, Recife, PE 52171-900, Brazil. E-mail: hubervet@gmail.com

The objective was to evaluate the occurrence, clinical signs and risk factors associated with seropositivity to Toxoplasma gondii and Neospora caninum in sheep. We used 294 sheep with history of reproductive disorders from 28 farms located in the state of São Paulo, southeastern Brazil. Producers were interviewed, and blood samples were collected to perform indirect immunofluorescence tests (1:64 and 1:50 respectively). The frequency of T. gondii infection was found to be $29.9 \%$ (88/294), the frequency of $N$. caninum was $18 \%(53 / 294)$, and $3.7 \%(11 / 294)$ of the sheep were seropositive for both. We observed the following risk factors associated with T. gondii infection: crossbred sheep $(\mathrm{p}=0.04)$, Santa Inês breed $(\mathrm{p}=0.006)$, pasture supply $(\mathrm{p}<0.001)$ or associated with concentrate $(\mathrm{p}<0.001)$, exclusive use of natural breeding $(\mathrm{p}=0.002)$, and presence of birds on farms $(\mathrm{p}=0.001)$. For $N$. caninum the factors were: female sheep $(\mathrm{p}=0.031)$, absence of barns $(\mathrm{p}<0.001)$, and semi-intensive system $(\mathrm{p}<0.001)$. In relation to the history of reproductive problems, $N$. caninum and T. gondii infected sheep presented a reduction in the risk of having an abortion $(\mathrm{p}=0.044)$ and repeated estrus $(\mathrm{p}=0.025)$ respectively. T. gondii was more serologically present than $N$. caninum in sheep with a history of reproductive disorders and, despite their similarities, differed epidemiologically in aspects related to breeding characteristics such as race, sex, breeding system, type of feeding and reproductive management.
\end{abstract}

INDEX TERMS: Antibodies, anti-Toxoplasma gondii, anti-Neospora caninum, risk factors, sheep, reproductive disorders, abortion, toxoplasmosis, neosporosis, repeat breading, parasitoses.

RESUMO.- Objetivou-se avaliar a ocorrência, sinais clínicos e fatores de risco associados a soropositividade para Toxoplasma gondii e Neospora caninum em ovinos.

\footnotetext{
${ }^{1}$ Recebido em 7 de junho de 2017.

Aceito para publicação em 21 de junho de 2017.

${ }^{2}$ Departamento de Medicina Veterinária, Universidade Federal Rural de Pernambuco (UFRPE), Rua Dom Manoel Medeiros s/n, Recife, PE 52171-900, Brasil. *Autor para correspondência: hubervet@gmail.com

${ }^{3}$ Laboratório de Raiva e Encefalites Virais, Instituto Biológico de São Paulo, Av. Conselheiro Rodrigues Alves 1.252, São Paulo, SP 04014-002, Brasil.

${ }^{4}$ Faculdade de Medicina Veterinária e Zootecnia (FMVZ), Universidade de São Paulo (USP), Avenida Prof. Dr. Orlando Marques de Paiva 87, Cidade Universitária, São Paulo, SP 05508-270.

${ }^{5}$ Instituto de Matemática e Estatística, Universidade de São Paulo (USP), Rua do Matão 1010, Cidade Universitária, São Paulo, SP 05508-090.
}

Foram utilizados 294 animais com histórico de distúrbios reprodutivos de 28 fazendas do estado de São Paulo, Brasil, diagnosticados através da imunofluorescência indireta (1:64 e 1:50). A ocorrência de T. gondii foi de 29,9\% (88/294) e de $N$. caninum $18 \%(53 / 294)$, sendo $3,7 \%(11 / 294)$ dos ovinos soropositivos para ambos. Observou-se com maiores chances à infecção pelo T. gondii: ovinos mestiços $(p=0,04)$, Santa Inês $(p=0,006)$, fornecimento de pastagem $(p<0,001)$ ou associada a concentrado $(p<0,001)$, uso exclusivamente de monta natural $(\mathrm{p}=0,002, \mathrm{OR}=2,28 \mathrm{e}$ IC95\%=1,37-3,79) e a presença de aves nas propriedades $(\mathrm{p}=0,001)$. Na infecção por $N$. caninum essa chance aumentou em: fêmeas $(p=0,031)$, propriedades sem aprisco $(p<0,001)$ e sistema de criação semi-intensivo $(p<0,001)$. Em relação ao histórico de problemas reprodutivos, ovelhas infectadas 
pelo $N$. caninum e T. gondii apresentaram redução da chance de apresentarem abortamento $(p=0,044)$ e repetição de estro $(\mathrm{p}=0,025)$ respectivamente. 0 T. gondii esteve mais presente sorologicamente que o $N$. caninum em ovinos com histórico de distúrbios reprodutivos e apesar de suas semelhanças, diferiram epidemiologicamente em aspectos relacionados as características da criação como raça, sexo, sistema de criação, tipo de alimentação e manejo reprodutivo.

TERMOS DE INDEXAÇÃO: Anticorpos, anti-Toxoplasma gondii, anti-Neospora caninum, fatores de risco, ovinos, distúrbios reprodutivos, aborto, toxoplasmose, neosporose, repetição de cio, parasitoses.

\section{INTRODUÇÃO}

A produtividade das explorações de ovinos depende muito de sua eficiência reprodutiva, e dois agentes que estão intimamente relacionados a essas perdas são Toxoplasma gondii e Neospora caninum que são parasitos protozoários do filo Apicomplexa estreitamente relacionados, embora apresentem diferenças filogenéticas, ultraestruturais, antigênicas e biológicas (Silva et al. 2013a, 2013b).

A toxoplasmose é uma das doenças parasitárias mais importantes da ovinocultura (Silva et al. 2013b). Entre os animais de criação, cabras, ovelhas e porcos são geralmente mais sensíveis à infecção em comparação com bovinos, equinos e aves, que raramente apresentam sintomas (Millar et al. 2008). Perdas devido a toxoplasmose durante a prenhez afeta cerca de 1,4-3,9\% dos rebanhos ovinos, o que corresponde a um prejuízo de 1.4-4.700.000 dólares (Freyre et al. 1999), principalmente devido aos abortamentos (Morley et al. 2008, Gabardo et al. 2013). Geralmente as ovelhas não apresentam sintomas no caso de uma infecção natural por T. gondii, exceto em casos raros de retenção de placenta (Dubey \& Kirkbride 1989), ou o desenvolvimento de cistos no tecido do sistema nervoso e muscular. Estudos sorológicos realizados em ovinos mostraram que a frequência da infecção por $T$. gondii varia de $1,8 \%$ a $95,7 \%$, dependendo da região do mundo e os testes de diagnóstico aplicados (Silva et al. 2013b).

No caso da neosporose em ovinos, estudos em âmbito nacional apresentaram variação de 1,8 a 64,2\% de soropositivos (Silva et al. 2013a). Figliuolo et al. (2004) estimaram uma prevalência de zero a $22,7 \%$ em trinta propriedades de São Paulo. É uma doença infecciosa da reprodução responsável por casos de aborto e mortalidade neonatal em ruminantes, principalmente em bovinos (Wilson et al. 2016), no entanto pesquisadores vêm alertando quanto aos distúrbios em ovinos (Moreno et al. 2012, Arranz-Solís et al. 2015), como os relatados no Brasil (Moore 2005, Moreno et al. 2012, Pinto et al. 2012), onde foi isolado e sequenciado pela primeira vez em 2007 (Pena et al. 2007).

Estudos sobre a neosporose demonstraram que algumas raças, o sistema de criação extensivo, pequenos produtores (<30 ha), utilização de pastagens comuns, vários tipos de fontes de água e a presença de mais de um cão resultou em uma maior probabilidade de os animais serem diagnosticados como soropositivos (Al-Majali et al. 2008, Farias et al. 2010, Paiz et al. 2015). Em bovinos leiteiros, cada cão presente na propriedade rural, aumentou em 1,13 vezes a probabilidade de infecção (Corbellini et al. 2006); no entanto, outros estudos com ovinos não observaram associação entre a presença de cães e ovinos sorospositivos sugerindo uma transmissão preferencialmente vertical nestes casos (Figliuolo et al. 2004, Romanelli et al. 2007, Soares et al. 2009, Souza Neto et al. 2009, Moura et al. 2014)

Ovinos são infectados por T. gondii através da ingestão de pastagem e água contaminadas por oocistos liberados nas fezes de gatos, que são o hospedeiro definitivo do parasita (Esteban-Redondo \& Innes 1997, Silva et al. 2013 b), enquanto no caso da neosporose essa função cabe aos canídeos (Silva et al. 2013a). A soropositividade para essas enfermidades está relacionada com a contaminação ambiental (Frenkel et al. 1975), principalmente em regiões úmidas devido a formação de um microambiente favorável à manutenção de oocistos viáveis no solo (Pita Gondim et al. 1999, Silva et al. 2003), havendo também correlação entre as fontes de água e a infecção oral (Romanelli et al. 2007). Há ainda a possibilidade de transmissão congênita e via sêmen (Lopes et al. 2013, Santos et al. 2016, Azevedo Filho et al. 2017, Consalter et al. 2017) causando transtornos reprodutivos nas fêmeas infectadas, como absorção fetal, morte embrionária e aborto (Syed-Hussain et al. 2015).

A toxoplasmose e neosporose são caracterizadas como doenças responsáveis por grandes perdas econômicas na exploração de ovinos, tornando-se necessária a realização de estudos que ajudem a melhor compreender seus aspectos. Os objetivos do presente estudo foram analisar ocorrência de anticorpos anti-T. gondii e anti-N. caninum e os fatores de risco para ovinos com distúrbios reprodutivos.

\section{MATERIAIS E MÉTODOS}

A pesquisa foi desenvolvida na Faculdade de Medicina Veterinária e Zootecnia da Universidade de São Paulo (FMVZ-USP) após aprovação do projeto pelo Comitê de Bioética da FMVZ/USP, protocolo no $1153 / 2007$.

As coletas foram realizadas, em propriedades localizadas no Estado de São Paulo, entre os anos de 2008 e 2009, sendo utilizados soros de ovinos, acima de um ano e com histórico de um ou mais transtornos reprodutivos, totalizando 294 amostras (257 ovelhas e 37 carneiros). Entre as ovelhas, os distúrbios reprodutivos observados incluíram aborto, endometrite, malformação fetal, nascimento de cordeiros fracos, natimorto, distocia, parto prematuro, presença de secreções uterinas, prolapso uterino, repetição de cio, infertilidade e/ou retenção de placenta. Os distúrbios nos carneiros incluíram infertilidade, degeneração, hiperplasia e hipoplasia testicular, orquite, epididimite e/ou baixo libido. Estes dados foram inseridos em registros clínicos, juntamente com os obtidos a partir do exame ginecológico (hiperemia da mucosa, mucosa pálida, presença de nódulos, petéquias, pústulas, telangiectasia e vesículas), andrológico (orquite, epididimite e infertilidade) e das características das fazendas (raça, sistema de produção, instalações, manejo alimentar, manejo reprodutivo, presença de outras espécies de animais na propriedade). Os ovinos eram oriundos de 28 propriedades rurais localizadas em dezenove cidades do Estado de São Paulo (Atibaia (3), Campinas (1), Cunha (1), Indaiatuba (1), Itapevi (1), Itatinga (1), Itu (2), Itupeva (1), Jundiaí (3), Morungaba (2), Pedra Bela (3), Piedade (1), Piracaia (1), Pirassununga (1), Santa Rita do Passa Quatro (1), Santo Anastácio (1), São Paulo (1), Valinhos (1) e Vargem (2). Os animais foram submetidos 
individualmente a exame clínico geral e do trato genital de acordo com os critérios recomendados por Antón \& Mayayo (2007).

As amostras de sangue foram coletadas por punção venosa, da veia jugular em tubo a vácuo, sem anticoagulante, centrifugadas a 1600 RPM por 10 minutos, e os soros foram acondicionados em microtubos e congelados a $-20^{\circ} \mathrm{C}$ até o momento da análise. A presença de anticorpos anti-Toxoplasma gondii e anti-Neospora caninum, foi investigada através da reação de imunofluorescência indireta (RIFI) de acordo com Camargo (1964), através de lâminas sensibilizados com taquizoítos de T. gondii ou N. caninum (Imunodot, Imunoteste $^{\circledR}$ T. gondii e $N$. caninum), examinadas sob microscopia de luz, com objetiva de quarenta e ocular de dez vezes. Foi utilizado um conjugado com FITC comercial (KPL; anticorpo de coelho anti IGG de ovelha). 0 diagnóstico sorológico da infecção pelo T. gondii e $N$. caninum foi estabelecido por meio de RIFI, utilizando ponto de corte para a triagem 1:64 e 1:50 respectivamente. 0 soro foi considerado positivo quando a fluorescência ocorreu em toda a superfície dos taquizoítos de N. caninum ou T. gondii e negativa quando a fluorescência era apical ou ausente (Paré et al. 1995). As lâminas foram analisadas em microscópio de fluorescência com lente objetiva de 40x.

A reação em cadeia da polimerase (PCR) para a detecção de T. gondii ou N. caninum foi realizada em cinco fetos abortados por quatro fêmeas. Para a identificação de T. gondii, foi extraído o DNA genômico em seguida empregado o método de amplificação do mesmo descrito por Homan et al. (2000), no qual foram utilizados oligonucleotídeos iniciadores específicos para o gênero Toxoplasma (Tox4 e Tox5), com obtenção de fragmentos de 529 pb (Garcia et al. 2006). A detecção de $N$. caninum foi realizada de acordo com o procedimento descrito por Hughes et al. (2006) e Barratt et al. (2008), cujas reações foram baseadas na amplificação das sequências do gene Nc5 do DNA genômico e ITS1 do DNA ribossomal respectivamente, que posteriormente foram submetidos a eletroforese onde os fragmentos de DNA foram comparados com padrão de peso molecular de $100 \mathrm{pb}$.

A determinação das frequências absolutas e relativas foi obtida através da análise estatística descritiva. Para o estudo dos fatores de risco associados à infecção por T. gondii e N. caninum, foi realizada a análise univariada das variáveis de interesse pelo teste qui-quadrado de Pearson, ou Exato de Fisher, quando necessário. Posteriormente, foi realizada a análise de regressão logística considerando como variável dependente para a infecção por T. gondii ou N. caninum o resultado da RIFI (positivo ou negativo). As variáveis independentes ou explanatórias consideradas no modelo foram aquelas que apresentaram significância estatística $<0,05$. Essa probabilidade foi estipulada para que possíveis fatores de risco do evento não fossem excluídos da análise (Hosmer \& Lemeshow 1989). A análise estatística foi realizada utilizando R.2.7.1 (www.r-project.org), Minitab 14 e software SPSS versão 15.

\section{RESULTADOS}

A frequência de ovinos soropositivos a Toxoplasma gondii foi de $29,9 \%$ (88/294), sendo numericamente maior entre ovelhas $(30,7 \%)$ quando comparado com carneiros (24,3\%), p=0,430. Já a de Neospora caninum foi de 18\% (53/294), sendo 20,2\% (52/254) entre as fêmeas e 2,7\% (1/37) entre os machos, com ovelhas apresentando mais possibilidade de infecção em relação aos carneiros ( $\mathrm{p}=0,031,0 \mathrm{R}=9,13$ e IC 95\%=1,22-68,16).
A ocorrência de propriedades, com ao menos um ovino soropositivo para um dos agentes do estudo, foi de $75 \%(21 / 29)$.

Os efeitos de sexo, raça, sistema de produção, instalações, manejo alimentar e reprodutivo, presença de outras espécies animais na propriedade sobre o risco de ovelhas serem soropositivas para T. gondii ou N. caninum são descritos no Quadro 1.

A toxoplasmose esteve presente independente do sistema de produção, com taxas de soropositivos de $25 \%$ e $31 \%$ ( $\mathrm{p}=0,26)$, respectivamente, para os sistemas intensivo e semiintensivo. Ovinos de raças lanadas apresentaram-se menos susceptíveis a infecção por T. gondii que os das raças Santa Inês $(p=0,006,0 R=2,43$ e IC 95\%=1,29-4,57) e mestiços ( $p=0,04,0 R=3,00$ e IC 95\%=1,05-8,54).

Em relação a neosporose os animais criados sob o sistema semi-intensivo apresentaram 7,86 mais possibilidades de serem soropositivos ( $\mathrm{p}<0,001$, IC 95\%=2,37-25,88), quando comparado com animais criados no sistema intensivo, com taxas de $23 \%$ e $3,8 \%$ de soropositivos, respectivamente. Além disso, rebanhos que não possuíam aprisco foram 9,58 (p<0,001, IC 95\%=4,19-19,60) mais propensos a apresentarem ovinos soropositivos para N. caninum.

Em relação ao manejo alimentar, no que se diz respeito à toxoplasmose, quando avaliamos o tipo de alimento fornecido observou-se maior risco de infecção quando o rebanho recebe exclusivamente pastagem ( $\mathrm{p}<0,001,0 \mathrm{R}=4,27$ e IC 95\%=1,98-9,20), seguida pelo fornecimento de pastagem e alimento concentrado ( $p<0,001,0 R=3,93$ e IC 95\%=1,99-7,73). Não foi observada relação entre a presença de animais soropositivos ao $N$. caninum e o tipo de alimento fornecido $(\mathrm{p} \geq 0,05)$.

Rebanhos que utilizavam exclusivamente a monta natural, como manejo reprodutivo, apresentaram-se 2,28 ( $p=0,002$ e IC 95\%=1,37-3,79) vezes mais propensos a apresentar ovelhas infectadas do que rebanhos submetidos ao manejo reprodutivo misto, utilizando a monta natural bem como as biotecnologias.

Quanto à criação consorciada de outras espécies, a presença de aves nas propriedades aumentou o risco de contaminação por T. gondii, por 2,49 vezes ( $\mathrm{p}=0,001$, IC 95\%=1,49-4,17), enquanto a presença de felinos, bovinos e caninos não afetaram de forma significativa o risco de infecção aos protozoários $(p \geq 0,05)$.

Nenhuma correlação significativa foi observada entre a infecção por T. gondii e/ou N. caninum e os sinais clínicos observados durante o exame ginecológico (Quadro 2) e andrológico (Quadro 3), realizados no momento da coleta do material biológico.

Em relação ao histórico de problemas reprodutivos relatados, foi observado valores significantes apenas quanto a ocorrência de abortamento e repetição de estro (Quadro 4), onde ovelhas infectadas por $N$. caninum e T. gondii apresentaram redução do risco de abortamento ( $\mathrm{p}=0,044,0 \mathrm{R}=0,53$, IC $95 \%=0,29-0,98)$ e repetição de estro ( $\mathrm{p}=0,025, \mathrm{OR}=0,49$, IC 95\%=0,26-0,92) respectivamente (Quadro 5).

A taxa de animais que foram concomitantemente soropositivas para ambos os protozoários foi de 3,74\% (11/294). Não foi detectado o DNA genômico dos parasitas, pesquisados através da PCR, em nenhum dos cinco fetos ovinos abortados. 


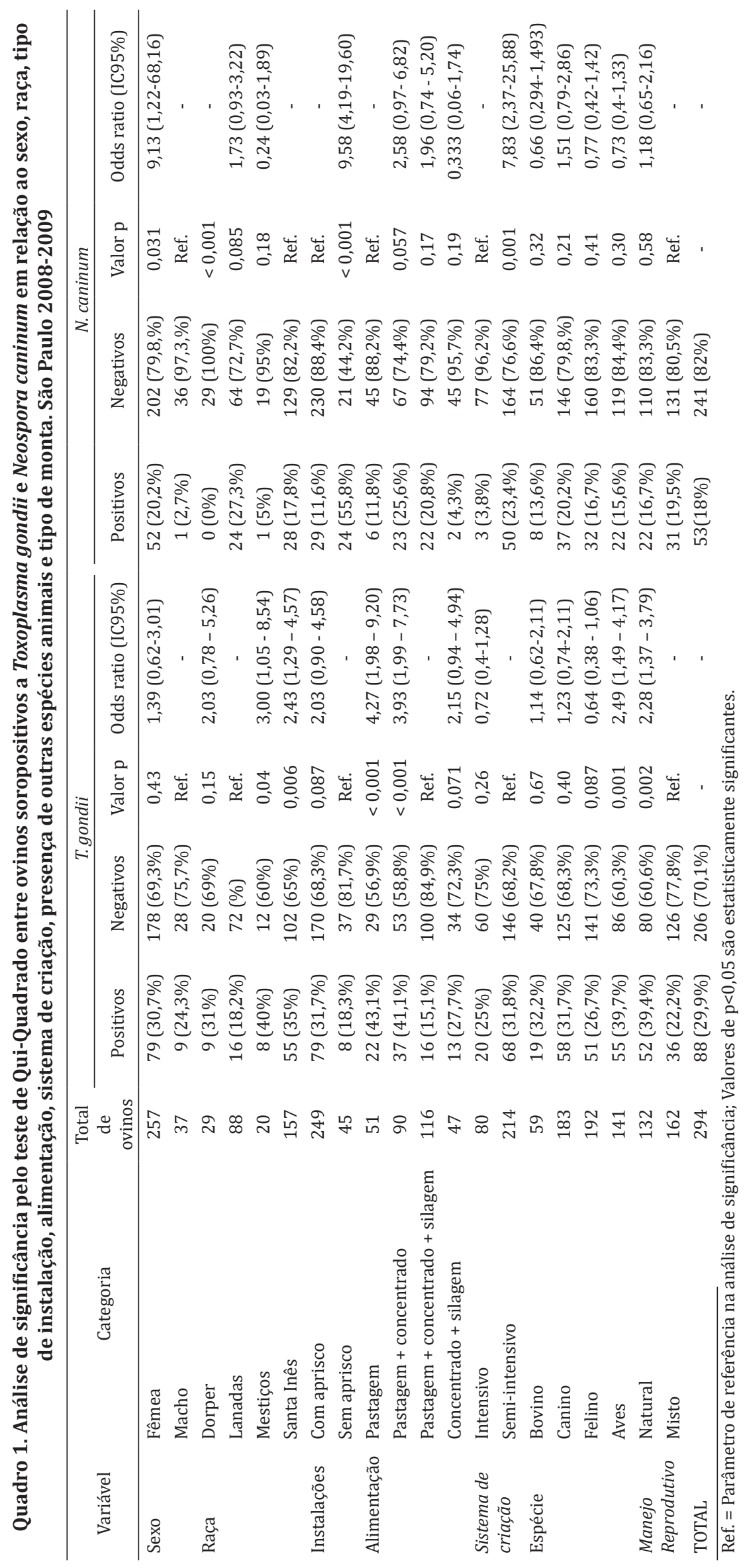


Quadro 2. Análise de significância pelo teste de Qui-Quadrado entre ovelhas soropositivas a Toxoplasma gondii e Neospora caninum em relação à presença ou não de sinais clínicos no momento do exame ginecológico. São Paulo 2008 -2009

\begin{tabular}{|c|c|c|c|c|c|c|}
\hline \multirow{2}{*}{ Variáveis } & \multirow{2}{*}{ Categoria } & \multirow{2}{*}{ Total de ovinos } & \multicolumn{2}{|c|}{ T. gondii } & \multicolumn{2}{|c|}{ N. caninum } \\
\hline & & & Positivos & Valor $\mathrm{p}$ & Positivos & Valor $\mathrm{p}$ \\
\hline \multirow[t]{2}{*}{ Mucosa hipercorada } & Sim & 46 & $11(23,9 \%)$ & 0,27 & $5(10,9 \%)$ & 0,09 \\
\hline & Não & 211 & $68(32,2 \%)$ & & $47(22,3 \%)$ & \\
\hline \multirow[t]{2}{*}{ Mucosa hipocorada } & Sim & 13 & $4(30,8 \%)$ & 0,99 & $4(30,8 \%)$ & 0,34 \\
\hline & Não & 244 & $75(30,7 \%)$ & & $48(19,7 \%)$ & \\
\hline \multirow[t]{2}{*}{ Nódulos } & Presente & 15 & $6(40 \%)$ & 0,43 & $2(13,3 \%)$ & 0,98 \\
\hline & Ausente & 242 & $73(30,2 \%)$ & & $51(20,2 \%)$ & \\
\hline \multirow[t]{2}{*}{ Petéquias } & Presente & 5 & $3(60 \%)$ & 0,18 & $1(20 \%)$ & 0,99 \\
\hline & Ausente & 252 & $76(30,2 \%)$ & & $52(20,4 \%)$ & \\
\hline \multirow[t]{2}{*}{ Pústulas } & Presente & 2 & $0(0 \%)$ & - & $0(0 \%)$ & - \\
\hline & Ausente & 255 & $79(31 \%)$ & & $51(23,3 \%)$ & \\
\hline \multirow[t]{2}{*}{ Secreções } & Presente & 38 & $12(31,6 \%)$ & 0,90 & $1(2,6 \%)$ & 0,018 \\
\hline & Ausente & 219 & $67(30,6 \%)$ & & $51(23,3 \%)$ & \\
\hline \multirow[t]{2}{*}{ Telangectasia } & Presente & 28 & $9(32,1 \%)$ & 0,87 & 7 (25\%) & 0,51 \\
\hline & Ausente & 229 & $70(30,6 \%)$ & & $45(19,7 \%)$ & \\
\hline \multirow[t]{2}{*}{ Vesículas } & Presente & 1 & $1(100 \%)$ & - & $0(0 \%)$ & - \\
\hline & Ausente & 256 & $78(30,5 \%)$ & & $52(20,3 \%)$ & \\
\hline
\end{tabular}

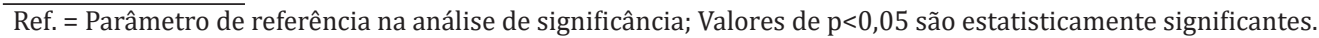

Quadro 3. Ocorrência de carneiros soropositivos a Toxoplasma gondii e Neospora caninum e a presença ou não de sinais clínicos no momento do exame andrológico. São Paulo 2008-2009

\begin{tabular}{lccc}
\hline \multicolumn{1}{c}{ Distúrbio Reprodutivo } & Total de ovinos & T. gondii & Positivos \\
\cline { 3 - 4 } & \multicolumn{1}{c}{ caninum } \\
Coixa fertilidade & 5 & $1(20 \%)$ & $0(0 \%)$ \\
Degeneração testicular & 23 & $4(17,4 \%)$ & $0(0 \%)$ \\
Falta de libido & 2 & $1(50 \%)$ & $0(0 \%)$ \\
Hiperplasia de epidídimo & 4 & $2(50 \%)$ & $0(0 \%)$ \\
Hiperplasia testicular unilateral & 1 & $0(0 \%)$ & $1(100 \%)$ \\
Total de carneiros & 2 & $1(50 \%)$ & $0(0 \%)$ \\
\end{tabular}

Quadro 4. Análise de significância pelo teste de Qui-Quadrado entre ovinos soropositivos a Toxoplasma gondii e Neospora caninum em relação à presença ou não de distúrbios reprodutivos no histórico de fêmeas ovinas. São Paulo, 2008 -2009

\begin{tabular}{|c|c|c|c|c|c|c|}
\hline \multirow{2}{*}{ Variáveis } & \multirow{2}{*}{ Categoria } & \multirow{2}{*}{ Total de ovinos } & \multicolumn{2}{|c|}{ T. gondii } & \multicolumn{2}{|c|}{ N. caninum } \\
\hline & & & Positivos & Valor $\mathrm{p}$ & Positivos & Valor $\mathrm{p}$ \\
\hline \multirow[t]{2}{*}{ Aborto } & Sim & 136 & $48(35,3 \%)$ & 0,094 & $21(15,4 \%)$ & 0,044 \\
\hline & Não & 121 & $31(25,6 \%)$ & & $31(25,6 \%)$ & \\
\hline \multirow[t]{2}{*}{ Endometrite } & Sim & 6 & $1(16,7 \%)$ & 0,46 & $0(0,0 \%)$ & - \\
\hline & Não & 251 & $78(31,1 \%)$ & & $52(20,3 \%)$ & \\
\hline \multirow[t]{2}{*}{ Malformação fetal } & Sim & 3 & $1(33,3 \%)$ & 0,92 & $0(0,0 \%)$ & - \\
\hline & Não & 254 & $78(30,7 \%)$ & & $52(20,5 \%)$ & \\
\hline \multirow[t]{2}{*}{ Morte neonatal } & Sim & 34 & $11(32,4 \%)$ & 0,83 & $9(26,5 \%)$ & 0,33 \\
\hline & Não & 223 & $68(30,5 \%)$ & & $43(19,3 \%)$ & \\
\hline \multirow{2}{*}{$\begin{array}{l}\text { Nascimento cordeiro } \\
\text { fraco }\end{array}$} & Sim & 30 & 7 (23,3\%) & 0,35 & $7(23,3 \%)$ & 0,65 \\
\hline & Não & 227 & $72(31,7 \%)$ & & $45(19,8 \%)$ & \\
\hline \multirow[t]{2}{*}{ Natimortalidade } & Sim & 7 & $2(28,6 \%)$ & 0,90 & $0(0,0 \%)$ & - \\
\hline & Não & 250 & $77(30,8 \%)$ & & $52(20,8 \%)$ & \\
\hline \multirow[t]{2}{*}{ Parto distócico } & Sim & 6 & $2(33,3 \%)$ & 0,89 & $0(0,0 \%)$ & - \\
\hline & Não & 251 & $77(30,7 \%)$ & & $52(20,7 \%)$ & \\
\hline \multirow[t]{2}{*}{ Parto prematuro } & Sim & 3 & $2(66,6 \%)$ & 0,22 & $0(0,0 \%)$ & - \\
\hline & Não & 254 & $77(30,3 \%)$ & & $52(20,5 \%)$ & \\
\hline \multirow[t]{2}{*}{ Prolapso uterino } & Sim & 2 & $0(0,0 \%)$ & - & $0(0,0 \%)$ & - \\
\hline & Não & 255 & $79(31,0 \%)$ & & $52(20,4 \%)$ & \\
\hline \multirow[t]{2}{*}{ Repetição de cio } & Sim & 77 & $16(20,8 \%)$ & 0,025 & $21(27,3 \%)$ & 0,068 \\
\hline & Não & 180 & $63(35,0 \%)$ & & $31(17,2 \%)$ & \\
\hline \multirow[t]{2}{*}{ Retenção de placenta } & Sim & 3 & $0(0,0 \%)$ & - & $0(0,0 \%)$ & - \\
\hline & Não & 254 & $79(31,1 \%)$ & & $52(20,5 \%)$ & \\
\hline
\end{tabular}

Ref. = Parâmetro de referência na análise de significância; Valores de p<0,05 são estatisticamente significantes. 
Quadro 5. Análise de regressão logística dos fatores de risco da presença de distúrbios reprodutivos em ovinos infectados por Toxoplasma gondii e Neospora caninum. São Paulo, 2008-2009

\begin{tabular}{|c|c|c|c|c|}
\hline \multirow{2}{*}{ Variável } & \multicolumn{2}{|c|}{ T. gondii } & \multicolumn{2}{|c|}{ N. caninum } \\
\hline & Valor $\mathrm{p}$ & Odds ratio (IC 95\%) & Valor $\mathrm{p}$ & Odds ratio (IC 95\%) \\
\hline Aborto & 0,094 & $1,58(0,92-2,71)$ & 0,044 & $0,53(0,29-0,98)$ \\
\hline Repetição de cio & 0,025 & $0,49(0,26-0,92)$ & 0,068 & $1,80(0,96-3,40)$ \\
\hline
\end{tabular}

Valores de $\mathrm{p}<0,05$ são estatisticamente significantes.

\section{DISCUSSÃO}

A soroprevalência de Toxoplasma gondii apresenta grande variação de acordo com a área pesquisada. No presente estudo, 29,9\% dos animais foram soropositivos, similar ao que foi observado por outros autores no estado de São Paulo (Meireles et al. 2003, Figliuolo et al. 2004, Felicio et al. 2008), mas inferior a ocorrência relatada na microrregião de Jaboticabal de 52\% (Lopes et al. 2010). Trabalho realizado no Estado de Pernambuco, utilizando rebanhos com histórico de problemas reprodutivos, apresentaram valores inferiores $(16,9 \%)$ de soropositivos (Pereira et al. 2012). A ocorrência de propriedades com ovinos soropositivos foi de $75 \%$ (21/28), diferente, de outros relatos que observaram pelo menos um animal soropositivo em cada uma das fazendas investigadas (Ogawa et al. 2003, Figliuolo et al. 2004, Romanelli et al. 2007, Pinheiro Junior et al. 2009, Souza Neto et al. 2009, Thomaz-Soccol et al. 2009, Ueno et al. 2009, Lopes et al. 2010). No entanto no presente trabalho, o número de animais coletados por propriedade variou de um a 44, devido ao caráter do estudo de pesquisar apenas animais que apresentaram histórico de distúrbios reprodutivos, sendo assim justifica-se que propriedades onde foram coletadas poucas amostras não apresentarem animais soropositivos.

$\mathrm{Na}$ ovinocultura a neosporose é relatada há 26 anos (Dubey \& Lindsay 1990), e no Brasil, os levantamentos realizados desde 2004 apontam frequências entre 1,8\% e $64,2 \%$ (Silva et al. 2013a). Neste estudo, com uma população de animais com histórico de falhas reprodutivas a frequência de animais soropositivos foi acima a de outros realizados em São Paulo que variou de 3\% a 12,4\% (Figliuolo et al. 2004, Cardoso et al. 2008, Langoni et al. 2011, Machado et al. 2011), com exceção do de Paiz et al. (2015) que utilizando ovinos de abatedouro obteve 52,6\% (90/170) de positivos. Desses levantamentos, somente de Figliuolo et al. (2004) utilizaram ponto de corte de 50, assim como esse estudo, nos demais o ponto foi de 25 , aumentando a possibilidade de animais sorologicamente positivos.

A frequência de ovinos soropositivos a T. gondii não foi influenciado pelo sexo, como relatado por outros autores (Ogawa et al. 2003, Souza Neto et al. 2009, Lopes et al. 2010, Guimarães et al. 2015), enquanto para a neosporose, ovelhas apresentaram 9,13 vezes mais chances de estarem infectadas que carneiros, achado esse que não foi relatado em outros estudos (Figliuolo et al. 2004, Romanelli et al. 2007, Ueno et al. 2009). As ovelhas, em geral, são mais expostas as pastagens que podem estar contaminadas com oocistos, enquanto reprodutores, características dos machos do estudo, eram criados em baias individuais ou com baixa lotação, semelhante ao sistema intensivo de criação. Sistema esse, que apresentou redução do risco de infecção ao N. caninum, nas propriedades que o adotavam.

Em relação à raça de ovinos, animais Santa Inês e mestiços foram mais propensos a serem soropositivo para T. gondii. Observou-se que as propriedades que possuíam esses ovinos visavam a produção cárnea, sendo os mesmos mantidos por mais tempo nas pastagens além de demonstrarem um controle sanitário menos rigoroso.

A presença de aprisco diminuiu o risco de animais soropositivos para N. caninum, sendo assim, podemos supor que o pasto seja mais acessível à invasão e eliminação de oocistos por cães em relação ao aprisco que possui portas e em alguns casos, como os de chão ripados, são suspensos, dificultando o acesso, corroborando com o resultado obtido em relação ao sistema de criação onde o intensivo se mostrou menos susceptível.

Quanto ao tipo de alimento fornecido, a predisposição a infecção ocorreu em relação ao T. gondii, onde ovinos que receberam exclusivamente pastagem ou associado a alimentos concentrados apresentaram maior risco quando comparado aos que se alimentavam de silagem e concentrado, que pode ocorrer devido a maior exposição aos oocistos no ambiente e no local de armazenamento (Zedda et al. 2010), corroborando com Moura et al. (2015) que avaliou ovinos exclusivamente a pasto e suplementados e Lopes et al. (2010) com dieta a pasto, concentrado e feno. 0 fornecimento de alimento concentrado em cocho comum para animais jovens e adultos também pode influenciar uma maior disseminação no rebanho (Pinheiro Júnior et al. 2009). Deve-se ter atenção quanto ao fornecimento de sal mineral onde os rebanhos que não recebem tal suplemento obtiveram uma maior ocorrência de ovinos soropositivos (Romanelli et al. 2007, Lopes et al. 2010) variável que não foi pesquisada nesse estudo.

0 presente estudo, assim como Guimarães et al. (2015) e Moura et al. (2015), não detectou correlação entre a presença de gatos nas propriedades e o aumentado do risco de infecção por T. gondii, como foi relatado por outros autores (Ogawa et al. 2003, Souza Neto et al. 2009, Brandão et al. 2009, Soares et al. 2009, Lopes et al. 2010). Cenci-Goga et al. (2013) relataram que os gatos residentes na fazenda não estariam correlacionados com ovinos soropositivos para T. gondii, e sim a presença de gatos errantes nas nascentes de água com o aumento do risco de infecção em 1,54 vezes. A presença de aves aumentou o risco de infecção por T. gondii em 2,49 vezes, onde a criação desses animais possa ser um atrativo para que gatos errantes adentrem as propriedades em busca de alimento contaminando, assim, as instalações. Fernandes et al. (2016) encontraram alta ocorrência de aves soropositivas $(40,6 \%)$ em criadouros da região metropolitana de Recife, onde nesses havia a presença de gatos, possíveis responsáveis 
pela contaminação do ambiente. A não observação da relação da presença de caninos e a infecção por Neospora caninum pode se dar devido a importância da transmissão vertical tanto em fêmeas infectadas antes e/ou durante a gestação (Syed-Hussain et al. 2015).

Propriedades que adotam exclusivamente a monta natural com manejo reprodutivo apresentaram um risco de infecção a T. gondii que foi 2,8 vezes maior em comparação com aqueles que também empregam alguma biotecnologia; sendo isso reflexo de um controle sanitário mais rígido nessas propriedades que são mais tecnificadas. No entanto, deve-se ater a presença do parasita em amostras de sêmen (Moraes et al. 2010) uma vez que se mantêm viável mesmo após o processo de envase e congelamento, servindo de via de infecção a fêmeas (Consalter et al. 2017).

Com relação aos sinais clínicos registados no exame ginecológico, nenhum deles foi correlacionada com a infecção por T. gondii ou N. caninum. Dubey \& Kirkbride (1989), relataram que, no caso de infecção natural, ovelhas geralmente não apresentam sintomas clínicos, exceto na ocorrência rara de retenção de placenta. Esta correlação não foi observada no presente estudo, pois os três animais que apresentaram retenção de placenta eram soronegativos para toxoplasma assim como para neospora.

Não foi observado, nesse estudo, a associação de ovinos soropositivos para T. gondii com quadros de abortamento, assim como relatado por Pereira et al. (2012) em relação a distúrbios reprodutivos em rebanhos da Zona da Mata e Agreste Pernambucano. Os abortamentos, no caso da toxoplasmose, estão mais relacionados a ovelhas onde a primo-infecção ocorre durante a gestação, sendo que sua consequência irá depender do período gestacional. A instalação do parasita no seu início poderá levar a morte e absorção fetal, no terço médio, ao aborto, principalmente até o septuagésimo dia de gestação e no terço final, geralmente resulta no nascimento de cordeiros viáveis e saudáveis, infectados ou não, devido a capacidade do organismo responder imunologicamente ao parasita (Miller et al. 1982, Buxton \& Henderson 1999). No entanto em rebanho de ovinos da raça Charolês foi observado quadros de transmissão congênita e sucessivos abortos em ovelhas soropositivas demonstrando a necessidade de maiores estudos quanto as cepas infectantes, sensibilidade de raças e imunidade relacionado a infecção por T. gondii (Morley et al. 2008).

A toxoplasmose destaca-se em estudos de distúrbios reprodutivos em ovinos, como na Itália, onde o seu agente foi o mais detectado pela PCR entre 292 amostras fetais e 76 de placentas (Masala et al. 2007) e na Espanha onde foi detectado em 23,1\% (40/176) das amostras de fetos abortados (Pereira-Bueno et al. 2004). Em rebanhos nacionais, T. gondii foi responsável por surto de abortamento e natimortalidae em rebanho de Minas Gerais (Gabardo et al. 2013) e diagnosticado através da imunoistoquímica em amostras de fetos abortados em terço final de gestação em ovinos da raça Sulfock criados no Rio Grande do Sul (Motta et al. 2008). Em propriedades do estado do Maranhão, que possuíam histórico de aborto, a presença de T. gondii foi 2,89 vezes maior em comparação com fazendas que faltam tais antecedentes (Brandão et al. 2009).

Notou-se fator de proteção quanto a repetição de estro e animais soropositivos a T. gondii, provavelmente devido desenvolvimento de imunidade duradoura e protetora para re-infecções, após a fase aguda, tornando rara a repetição de quadros de distúrbios reprodutivos (Beverley \& Watson 1971, Dubey \& Kirkbride 1989). Santos et al. (2016), em ovelhas Santa Inês primo-infectadas experimentalmente antes da prenhez e durante diferentes estágios gestacionais, apesar de nenhum caso de aborto, observaram distúrbios em cordeiros como; alterações locomotoras, malformações, natimortalidade e debilidade, indicando que nem sempre ocorra proteção do feto contra T. gondii nas reinfecções.

No presente trabalho, a infecção por $N$. caninum demonstrou diminuir o risco de aborto nas ovelhas, já em estudo de rebanhos de São Paulo, Machado et al. (2011) observaram relação entre ovinos soropositivos e a presença de distúrbios reprodutivos. Dubey \& Lindsay (1990) relataram que ovinos infectados experimentalmente aos dois meses de gestação, apresentaram casos de aborto ou absorção fetal, corroborando com os achados de Arranz-Solís et al. (2015) em ovelhas experimentalmente infectadas no primeiro e segundo terço de gestação, enquanto as infectadas no terço final apresentaram nascimento de cordeiros viáveis, embora alguns deles nascessem prematuros e fracos.

Pode-se especular que o grupo de ovelhas no estudo, que foi reativo ao parasita, podem ter sido infectadas no período pré gestacional concedendo a esses animais proteção imunológica, após a transformação de taquizoítos em bradizoítos, formando cistos teciduais, mantendo o hospedeiro na fase crônica da infecção na qual é assintomática, entretanto, se no período gestacional ocorrer redução da imunidade, a infecção pode ser reativada e os bradizoítos se transformarem em taquizoítos desenvolvendo a forma aguda da neosporose podendo levar ao abortamento (Buxton et al. 2002). Azevedo Filho et al. (2017) não observaram casos de abortos em treze ovelhas naturalmente infectadas antes da gestação, sendo que os títulos de anticorpos anti-T.gondii obtidos pelo ELISA reduziram de acordo com a proximidade do parto.

As alterações clínicas e distúrbios no trato reprodutivo, em carneiros do estudo, não tiveram relação significante com a soropositividade para os parasitas, corroborando com trabalhos que mostram ausência de alterações, principalmente em epidídimos e testículos, apesar de alguns dados de alterações no ejaculado de animais soropositivos que devem ser mais estudados para que se afirme uma correlação com a infecção (Lopes et al. 2009, Moraes et al. 2010). No entanto tem-se relatado a presença de $T$. gondii no trato reprodutivo de carneiros em amostras de sêmen, de ovinos infectados experimentalmente (Lopes et al. 2009) e naturalmente (Moraes et al. 2010) e em amostras de epidídimos de ovinos de abatedouro detectado pela PCR (Bezerra et al. 2013).

Uma série de estudos relata que a prevalência de $N$. caninum entre os rebanhos de ovinos geralmente é menor em comparação com T. gondii. A frequência de animais que foram concomitantemente soropositivas para ambos os agentes é geralmente baixo, Figliuolo et al. (2004) relataram a soropositividade para ambos os organismos em 3,5\% de 597 amostras, Romanelli et al. (2007), em 5,2\% de 305 amostras, Ueno et al. (2009), em 4,67\% de 1.028 amostras e Pandero et al. (2010), em 9\% de 177 amostras. No presente estudo, a taxa de animais que eram concomitantemente soropositivos para T. gondii e $N$. caninum também foi baixa, correspondendo $3,74 \%$ dos ovinos. 
A não detecção do DNA genômico dos parasitas pela PCR, em nenhum dos quatro fetos abortados, pode ser justificado pelos resultados do estudo que demonstram a não relação desses quadros de abortamento, com animais soropositivos, apresentando ainda uma situação de redução no caso de T. gondii, além de que, das quatro fêmeas que foram encaminhados os fetos abortados, apenas uma foi soropositiva ao T. gondii e nenhuma a $N$. caninum. Os fetos se encontravam em bom estado de conservação, no entanto não foram encaminhas as suas placentas, amostras essas que aumentam as chances de identificação do agente infeccioso (Pereira et al. 2013). Sendo assim outros agentes etiológicos, falhas de manejos, causas nutricionais, metabólicas e tóxicas podem estar envolvidos nesses casos de abortos (Mobini et al. 2004, Masala et al. 2007).

\section{CONCLUSÕES}

Toxoplasma gondii esteve mais presente sorologicamente que Neospora caninum em ovinos com histórico de distúrbios reprodutivos.

Apesar de suas semelhanças, por serem parasitas apicomplexos formadores de cistos, diferem em muitos aspectos epidemiológicos relacionados com características da criação como raça e sexo dos ovinos, sistema de criação, tipo de alimentação e manejo reprodutivo que devem ser levadas em consideração, sempre que se objetivar o controle dessas enfermidades causadas por protozoários.

A exposição à pastagem se mostrou fator impotânte na infecção dos ovinos estudados.

Agradecimentos.- À Fundação de Amparo à Pesquisa do Estado de São Paulo (FAPESP) pelo financiamento do estudo e pelas bolsas de estudo concedidas para a realização deste estudo.

\section{REFERÊNCIAS}

Al-Majali A.M., Jawasreh K.I., Talafha H.A. \& Talafha A.Q. 2008. Neosporosis in sheep and different breeds of goats from southern Jordan: prevalence and risk factors analysis. Am. J. Anim. Vet. Sci. 3(2):47-52. <http://dx.doi. org/10.3844/ajavsp.2008.47.52>

Antón J.J.R. \& Mayayo L.M.F. 2007. La Exploración Clínica del Ganado Ovino y su Entorno. Servet, Zaragoza. 422p.

Arranz-Solís D., Benavides J., Regidor-Cerrillo J., Fuertes M., Ferre I., Ferreras Mdel.C., Collantes-Fernández E., Hemphill A., Pérez V. \& Ortega-Mora L.M. 2015. Influence of the gestational stage on the clinical course, lesional develop ment and parasite distribution in experimental ovine neosporosis. Vet. Res. 46(1):19. <http://dx.doi.org/10.1186/s13567-014-0139-y> $<$ PMid:25884945>

Azevedo Filho P.C.G., Oliveira J.M.B., Andrade M.R., Silva J.G., Kima P.C.P., Almeida J.C.A., Porto W.J.N. \& Mota R.A. 2017. Incidence and vertical transmission rate of Neospora caninum in sheep. Comp. Immunol. Microbiol. Infect. Dis. 52:19-22. <http://dx.doi.org/10.1016/j.cimid.2017.05.006> $<$ PMid:28673457>

Barratt J., Al Qassab S., Reichel M.P. \& Ellis J.T. 2008. The development and evaluation of a nested PCR assay for detection of Neospora caninum and Hammondia heydorni in feral mouse tissues. Mol. Cell. Probes 22(4):228233. <http://dx.doi.org/10.1016/j.mcp.2008.03.001><PMid:18420378>

Beverley J.K.A. \& Watson W.A. 1971. Prevention of experimental and naturally occurring ovine abortion due to toxoplasmosis. Vet. Rec. 88(2):39-41. <http://dx.doi.org/10.1136/vr.88.2.39><PMid:5100590>
Bezerra M.J.G., Cruz J.A.L.O., Kung E.S., Melo R.P.B., Gomes A.L.V., Moraes É.P.B.X., Pinheiro Junior J.W. \& Mota R.A. 2013. Detecção de Toxoplasma gondii em órgãos do sistema reprodutivo de carneiros naturalmente infectados no Brasil. Pesq. Vet. Bras. 33(8):989-991. <http://dx.doi.org/10.1590/ S0100-736X2013000800007>

Brandão V.M., Costa F.B., Silva I.A., Silva D.F., Dias I.C.L., Gennari S.M., Souza J.R.S.T. \& Silva M.I.S. 2009. Levantamento soroepidemiológico da toxoplasmose em ovinos na ilha de São Luís, MA. Ciênc. Anim. Bras. 10(Supl. 1):720-725.

Buxton D. \& Henderson D. 1999. Infectious abortion in sheep. In Practice 21(7):360-368. <http://dx.doi.org/10.1136/inpract.21.7.360>

Buxton D., Mc Allister M.M. \& Dubey J.P. 2002. The comparative pathogenesis of neosporosis. Trends Parasitalogy 18(12):546-552. <http://dx.doi. org/10.1016/S1471-4922(02)02414-5><PMid:12482540>

Camargo M.E. 1964. Improved technique of indirect immunofluorescence for serological diagnosis of toxoplasmosis. Revta Inst. Med. Trop. 6:117118. <PMid:14177810>

Cardoso M.V., Lara M.C.C.S.H., Chiebao D., Gabriel F.H.L., Villalobos E.M.C., Paulin L.M., Castro V., Nassar A., Cunha E.M.S., Piatti R.M. \& Pituco E.M. 2008. Determinação da condição sanitária de rebanhos caprinos e ovinos na região sudoeste do estado de São Paulo, Brasil. Anais 35o Congresso Brasileiro de Medicina Veterinária, Gramado, SOVERGS. (Resumo)

Cenci-Goga B.T., Ciampelli A., Sechi P., Veronesi F., Moretta I., Cambiotti V. \& Thompson P.N. 2013. Seroprevalence and risk factors for Toxoplasma gondii in sheep in Grosseto district, BMC Vet. Res., Tuscany, 9:25.

Consalter A., Silva A.F., Frazão-Teixeira E., Matos L.F., de Oliveira F.C.R., Leite J.S., Silva F.B.F. \& Ferreira A.M.R. 2017. Toxoplasma gondii transmission by artificial insemination in sheep with experimentally contaminated frozen sêmen. Theriogenology 90(1):169-174. <http://dx.doi.org/10.1016/j. theriogenology.2016.12.004><PMid:28166964>

Corbellini L.G., Smith D.R., Pescador C.A., Schmitz M., Correa A., Steffen D.J. \& Driemeier D. 2006. Herd-level risk factors for Neospora caninum seroprevalence in dairy farms in southern Brazil. Prev. Vet. Med. 74(2/3):130-141. <http:// dx.doi.org/10.1016/j.prevetmed.2005.11.004> <PMid:16343669>

Dubey J.P. \& Kirkbride C.A. 1989. Enzootic toxoplasmosis in sheep in north-central United States. J. Parasitol. 75(5):673-676. <http://dx.doi. org/10.2307/3283047><PMid:2795369>

Dubey J.P. \& Lindsay D.S. 1990. Neopora caninum induced abortion in sheep. J. Vet. Diagn. Invest. 2(3):230-233.<http://dx.doi.org/10.1177/104063879000200316> <PMid:2094452>

Esteban-Redondo I. \& Innes E.A. 1997. Toxoplasma gondii infection in sheep and cattle. Comp. Immunol. Microbiol. 20(2):191-196. <http://dx.doi. org/10.1016/S0147-9571(96)00039-2><PMid:9208205>

Farias E., Cavalcanti E., Medeiros E., Pinheiro Júnior J.W., Azevedo S.S., Athayde A.C. \& Mota R.A. 2010. Risk factors associated with Neospora caninum seropositivity in sheep from the State of Alagoas, in the Northeast Region of Brazil. J. Parasitol. 96(1):197-199. <http://dx.doi.org/10.1645/ GE-2176.1><PMid:19799489>

Felicio P.S., Villalobos E.M.C., Lara M.C.C.S.H., Cunha E.M.S., Nogueira A.H.C., Chiebao D.P., Escocio C.S., Gabriel F.H.L. \& Genovez M.E. 2008. Frequência de anticorpos anti-Toxoplasma gondii (Nicolle et Manceaux, 1909) em ovinos na região de Sorocaba, São Paulo: dados preliminares. Arqs Inst. Biológico, São Paulo, 70(2):109.

Fernandes M.F.T.S., Cavalcanti E.F.T.S.F., Silva J.G., Mota A.R., Souza Neto O.L., Santos A.S., Albuquerque P.P.F., Lima D.C.V. \& Mota R.A. 2016. Occurrence of anti-Toxoplasma gondii antibodies and parasite DNA in backyard chicken breeding in Northeast, Brazil. Braz.J. Vet. Parasitol. 25(1):105-108.<http:// dx.doi.org/10.1590/S1984-29612016012><PMid:27007250>

Figliuolo L.P.C., Kasai N., Ragozo A.M.A., De Paula V.S.O., Dias R.A., Souza S.L.P. \& Gennari S.M. 2004. Prevalence of anti-Toxoplasma gondii and anti-Neospora caninum antibodies in ovine from São Paulo State, Brazil. Vet. Parasitol. 
123(3/4):161-166. <http://dx.doi.org/10.1016/j.vetpar.2004.06.006> $<$ PMid:15325042>

Frenkel J.K., Ruiz A. \& Chinchilla M. 1975. Soil survival of Toxoplasma oocysts in Kansas and Costa Rica. Am. J. Trop. Med. Hyg. 24(3):439-443. <http:// dx.doi.org/10.4269/ajtmh.1975.24.439><PMid:1098494>

Freyre A., Bonino J., Falcón J., Castells D., Correa O. \& Casaretto A. 1999. The incidence and economic significance of ovine toxoplasmosis in Uruguay. Vet. Parasitol. 81(1/2):85-88. <PMid:9950332>

Gabardo M.P., Oliveira J.S.V., Ecco R. \& Guedes R.M.C. 2013. Outbreak of ovine abortion by toxoplasmosis in southeastern Brazil. Braz. J. Vet. Pathol. 6(1):37-41.

Garcia J.L., Gennari S.M., Machado R.Z. \& Navarro I.T. 2006. Toxoplasma gondii: detection by mouse bioassay, histopathology, and polymerase chain reaction in tissues from experimentally infected pigs. Exp. Parasitol. 113(4):267-271. <http://dx.doi.org/10.1016/j.exppara.2006.02.001><PMid:16545804>

Guimarães A., Raimundo J.M., Moraes L.M.B., Silva A.T., Santos H.A., Pires M.S., Machado R.Z. \& Baldani C.D. 2015. Occurrences of anti-Toxoplasma gondii and anti-Neospora caninum antibodies in sheep from four districts of Tocantins state. Brazilian Legal Amazon Region. Pesq. Vet. Bras. 35(2):110114. <http://dx.doi.org/10.1590/S0100-736X2015000200002>

Homan W.L., Vercammen M., De Braekeleer J. \& Verschueren H. 2000. Identification of a 200 to 300 fold repetitive 529 bp DNA fragment in Toxoplasma gondii, and its use for diagnostic and quantitative PCR. Int. J. Parasitol.30(1):69-75. <http://dx.doi.org/10.1016/S0020-7519(99)001708> <PMid:10675747>

Hosmer D. \& Lemeshow S. 1989. Applied Logistic Regression. Wiley-Interscience Publication, John Wiley and Sons Inc., New York, NY. 307p.

Hughes M.J., Williams H.R., Morley K.E., Cook N.A.D., Terry S.R., Murphy G.R., Smith E.J. \& Hide G. 2006. The prevalence of Neospora caninum and co infection with Toxoplasma gondii by PCR analysis in naturally occurring mammal populations. Parasitology 132(1):29-36. <http://dx.doi. org/10.1017/S0031182005008784><PMid:16393351>

Langoni H., Greca Júnior H., Guimarães F.F., Ullmann L.S., Gaio F.C., Uehara R.S., Rosa E.P., Amorim R.M. \& Da Silva R.C. 2011. Serological profile of Toxoplasma gondii and Neospora caninum infection in commercial sheep from São Paulo State, Brazil. Vet. Parasitol. 177(1/2):50-54. <http://dx.doi. org/10.1016/j.vetpar.2010.11.024><PMid:21256676>

Lopes W.D.Z., Costa A.J., Souza F.A., Rodrigues J.D.F., Costa G.H.N., Soares V.E. \& Silva G.S. 2009. Semen variables of sheep (Ovis aries) experimentally infected with Toxoplasma gondii. Anim. Reprod. Sci. 111(2/4):312-319. <http://dx.doi.org/10.1016/j.anireprosci.2008.03.015><PMid:18448278>

Lopes W.D.Z., Santos T.R., Silva R.S., Rossanese W.M., Souza F.A., Rodrigues J.D.F., Mendonça R.P., Soares V.E. \& Costa A.J. 2010. Seroprevalence of and risk factors for Toxoplasma gondii in sheep raised in the Jaboticabal microregion, São Paulo State, Brazil. Res. Vet. Sci. 88(1):104-106. <http:// dx.doi.org/10.1016/j.rvsc.2009.06.006> <PMid:19589550>

Lopes W.D., Rodriguez J.D., Souza F.A., Santos T.R., Santos R.S., Rosanese W.M., Lopes W.R., Sakamoto C.A. \& Costa A.J. 2013. Sexual transmission of Toxoplasma gondii in sheep. Vet. Parasitol. 195(1/2):47-56. <http:// dx.doi.org/10.1016/j.vetpar.2012.12.056><PMid:23384578>

Machado G.P., Kikuti M., Langoni H. \& Paes A.C. 2011. Seroprevalence and risk factors associated with neosporosis in sheep and dogs from farms. Vet. Parasitol. 182(2/4):356-358. <http://dx.doi.org/10.1016/j. vetpar.2011.05.021 ><PMid:21676548>

Masala G., Porcu R., Daga C., Denti S., Canu G., Patta C. \& Tola S. 2007. Detection of pathogens in ovine and caprine abortion samples from Sardinia, Italy, by PCR. J. Vet. Diagn. Invest. 19(1):96-98. <http://dx.doi. org/10.1177/104063870701900116><PMid:17459840>

Meireles L.R., Galisteo Junior A.J. \& Andrade Junior H.F. 2003. Serological survey of antibodies to Toxoplasma gondii in food animals from São Paulo state, Brazil. Braz. J. Vet. Res. Anim. Sci. 40(4):267-271. <http://dx.doi org/10.1590/S1413-95962003000400005>

Millar P.R., Sobreiro L.G., Bonna I.C.F. \& Amendoeira M.R.R.A. 2008. Importância dos animais de produção na infecção por Toxoplasma gondii no Brasil. Semina, Ciênc. Agrárias 29(3):693-706.

Miller J., Blewett D.A. \& Buxton D. 1982. Clinical and serological response of pregnant gimmers to experimental induced toxoplasmosis. Vet. Rec. 111(6):124-126.<http://dx.doi.org/10.1136/vr.111.6.124><PMid:7123831>

Mobini S., Heath A.M. \& Pugh D.G. 2004. Teriogenologia de ovinos e caprinos, p.145-208. In: Pugh D.G. (Ed.), Clínica de Ovinos e Caprinos. Roca, São Paulo.

Moore D.P. 2005. Neosporosis in South America. Vet. Parasitol. 127(2):87-97. <http://dx.doi.org/10.1016/j.vetpar.2004.10.001> <PMid:15631900>

Moraes E.P.B.X., Faria E.B., Batista A.M., Freitas A.C., Silva J.C.R., Albuquerque P.P.F. \& Mota R.A. 2010. Detecção de Toxoplasma gondii no sêmen de ovinos naturalmente infectados. Pesq. Vet. Bras. 30(11):915-917.<http://dx.doi. org/10.1590/S0100-736X2010001100003>

Moreno B., Collantes-Fernández E., Villa A., Navarro A., Regidor-Cerrillo J. \& Ortega-Mora L.M. 2012. Occurrence of Neospora caninum and Toxoplasma gondii infections in ovine and caprine abortions. Vet. Parasitol. 187(1/2):312318. <http://dx.doi.org/10.1016/j.vetpar.2011.12.034><PMid:22260901>

Morley E.K., Williams R.H., Hughes J.M., Thomasson D., Terry R.S., Duncanson P., Smith J.E. \& Hide G. 2008. Evidence that primary infection of Charollais sheep with Toxoplasma gondii may not prevent foetal infection and abortion in subsequent lambings. Parasitology 135(2):169-173. <http://dx.doi. org/10.1017/S0031182007003721><PMid:17922930>

Motta A.C., Vieira M.I.B., Bondan C., Edelweiss M.I.A., Dametto M.A. \& Gomes A. 2008. Aborto em ovinos associado à toxoplasmose: caracterização sorológica, anátomo-patológica e imunoistoquímica. Revta Bras. Parasitol. Vet. 17(Supl. 1):209-214.

Moura A.B., Güths M.F., Farias J.A., Souza A.P., Sartor A.A. \& Quadros R.M 2014. Neospora caninum seroprevalence and risk factors for ewes from Santa Catarina Plateau, Brazil. Semina, Ciênc. Agrárias 35(5):2591-2600.

Moura A.B., Silva M.O., Trevisani N., Souza A.P., Sartor A.A. \& Quadros R.M. 2015. Toxoplasma gondii: soroprevalência e fatores de risco em ovelhas no planalto serrano de Santa Catarina, Brasil. Revta Inst. Adolfo Lutz 74(3):200-206.

Ogawa L., Navarro I.T., Freire R.L., Oliveira R.C. \& Vidotto 0. 2003. Ocorrência de anticorpos anti-Toxoplasma gondii em ovinos da região de Londrina no Estado do Paraná. Ciência Rural 24(1):57-62.

Paiz L.M., da Silva R.C., Menozzi B.D. \& Langoni H. 2015. Antibodies to Neospora caninum in sheep from slaughter houses in the state of São Paulo, Brazil Braz. J. Vet. Parasitol. 24(1):95-100.<http://dx.doi.org/10.1590/S198429612015009><PMid:25909261>

Pandero R., Painceira A., López C., Vázquez L., Paz A., Díaz P., Dacal V., Cienfuegos S., Fernández G., Lago N., Díez-Baños P. \& Morrondo P. 2010 Seroprevalence of Toxoplasma gondii and Neospora caninum in wild and domestic ruminants sharing pastures in Galicia (Northwest Spain). Res. Vet. Sci. 88(1):111-115. <http://dx.doi.org/10.1016/j.rvsc.2009.05.010> <PMid:19482324>

Paré J., Hietala S.K. \& Thurmond M.C. 1995. Interpretation of an indirect fluorescent antibody test for diagnosis of Neospora sp. infection in cattle. J. Vet. Diagn. Invest. 7(2):273-275. <http://dx.doi.org/10.1177/104063879500700222> <PMid:7619917>

Pena H.F., Soares R.M., Ragozo A.M., Monteiro R.M., Yai L.E.O., Nishi S.M. \& Gennari S.M. 2007. Isolation and molecular detection of Neospora caninum from naturally infected sheep from Brazil. Vet. Parasitol. 147(1/2):61-66. <http://dx.doi.org/10.1016/j.vetpar.2007.03.002> <PMid:17451882>

Pereira-Bueno J., Quintanilla A., Pérez-Pérez V., Álvarez-García G., CollantesFernández E. \& Ortega-Mora L.M. 2004. Evaluation of ovine abortion associated with Toxoplasma gondii in Spain by different diagnostic 
techniques. Vet. Parasitol. 121(1/2):33-43.<http://dx.doi.org/10.1016/j. vetpar.2004.02.004 ><PMid:15110401>

Pereira M.F., Mota R.A., Peixoto R.M. \& Piatti R.M. 2013. Estudo de casos de aborto em caprinos e ovinos no estado de Pernambuco, Brasil. Ciênc. Vet. Tróp. 16(1/3):18-30.

Pereira M.F., Peixoto R.M., Langoni H., Greca Junior H., Azevedo S.S., Porto W.J.N., Medeiros E.S. \& Mota R.A. 2012. Fatores de risco associados à infecção por Toxoplasma gondii em ovinos e caprinos no estado de Pernambuco. Pesq. Vet. Bras. 32(2):140-146. <http://dx.doi.org/10.1590/S0100736X2012000200009>

Pinheiro Junior J.W., Mota R.A., Oliveira A.A.F., Faria E.B., Pita Gondim L.F., Silva A.V. \& Anderlini G.A. 2009. Prevalence and risk factors associated to infection by Toxoplasma gondii in ovine in the State of Alagoas, Brazil. Parasitol. Res. 105(3):709-715. <http://dx.doi.org/10.1007/s00436-0091472-3> <PMid:19468755>

Pinto A.P., Bacha F.B., Santos B.S., Driemeier D., Antoniassi N.A.B., Sá Ribas N.L.K. \& Lemos R.A.A. 2012. Sheep abortion associated with Neospora caninum in Mato Grosso do Sul, Brazil. Pesq. Vet. Bras. 32(8):739-742. <http://dx.doi.org/10.1590/S0100-736X2012000800010>

Pita Gondim L.F., Barbosa Junior H.V., Ribeiro Filho C.H.A. \& Saeki H. 1999. Serological survey of antibodies to Toxoplasma gondii in goats, sheep, cattle and water buffaloes in Bahia State, Brazil. Vet. Parasitol. 82(4):273-276. <http://dx.doi.org/10.1016/S0304-4017(99)00033-3><PMid:10384902>

Romanelli P.R., Freire R.L., Vidotto O., Marana E.R., Ogawa L., De Paula V.S., Garcia J.L. \& Navarro I.T. 2007. Prevalence of Neospora caninum and Toxoplasma gondii in sheep and dogs from Guarapuava farms, Paraná State, Brazil. Res. Vet. Sci. 82(2):202-207. <http://dx.doi.org/10.1016/j. rvsc.2006.04.001><PMid:17266999>

Santos T.R., Faria G.S.M., Guerreiro B.M., Dal Pietro N.H.P.S., Lopes W.D.Z., Silva H.M., Garcia J.L., Luvizotto M.C.R., Bresciani K.D.S. \& Costa A.J. 2016. Congenital toxoplasmosis in chronically infected and subsequently challenged ewes. Plos0ne 11(10):e0165124. <http://dx.doi.org/10.1371/ journal.pone.0165124><PMid:27788185>

Silva A.F., Brandão F.Z. \& Ferreira A.M.R. 2013a. Neosporose ovina: estado da arte. Revta Bras. Reprod. Anim. 37(1):45-52.

Silva A.F., Brandão F.Z., Oliveira F.C.R. \& Ferreira A.M.R. 2013b. Toxoplasma gondii in the sheep industry: a global overview and the situation in Brazil. Revta Bras. Ciênc. Vet. 20(4):179-188.
Silva A.V., Cunha E.L.P., Meireles L.R., Gottschalk S., Mota R.A. \& Langoni H.T. 2003. Toxoplasmose em ovinos e caprinos: estudo soroepidemiológico de duas Regiões do Estado de Pernambuco, Brasil. Ciência Rural 33(1):115119. <http://dx.doi.org/10.1590/S0103-84782003000100018>

Soares H.S., Ahid S.M., Bezerra A.C., Pena H.F., Dias R.A. \& Gennari S.M. 2009. Prevalence of anti-Toxoplasma gondii and anti-Neospora caninum antibodies in sheep from Mossoró, Rio Grande do Norte, Brazil. Vet. Parasitol. 160(3/4):211-214. <http://dx.doi.org/10.1016/j.vetpar.2008.10.102> $<$ PMid:19091473>

Souza Neto O.L., Albuquerque P.P.F., Santos A.S., Fernandes E.F.T.S., Faria E.B., Moraes E.P.B.X., Rabelo S.S.A., Silva L.B.G. \& Mota R.A. 2009. Prevalência de anticorpos IgG anti-Toxoplasma gondii e fatores de risco associados à infecção em caprinos e ovinos no município de Gravatá, PE. $9^{a}$ Jornada de Ensino, Pesquisa e Extensão (Jepex), Recife.

Syed-Hussain S.S., Howe L., Pomroy W.E., West D.M., Hardcastle M. \& Williamson N.B. 2015. Vertical transmission in experimentally infected sheep despite previous inoculation with Neospora caninum NcNZ1 isolate. Vet. Parasitol. 208(3/4):150-158. <http://dx.doi.org/10.1016/j.vetpar.2014.12.036> $<$ PMid:25638717>

Thomaz-Soccol V., Castro E.A., Gazda T.L., Garcia G., Richartz R.R.T.B. \& Dittrich R.L. 2009. Ocorrência de anticorpos anti-Toxoplasma gondii em ovinos das áreas urbanas e periurbanas de Curitiba, Paraná. Revta Bras. Parasitol. Vet. 18(Supl. 1):69-70. <http://dx.doi.org/10.4322/rbpv.018e1013>

Ueno T.E.H., Gonçalvez V.S.P., Heinemann M.B., Dilli T.L.B., Akimoto B.M., Souza S.L.P., Gennari S.M. \& Soares R.M. 2009. Prevalence of Toxoplasma gondii and Neospora caninum infections in sheep from Federal District, central region of Brazil. Trop. Anim. Health Prod. 41(4):547-552.<http://dx.doi. org/10.1007/s11250-008-9220-8><PMid:18726165>

Wilson D.J., Orsel K., Waddington J., Rajeev M., Sweeny A.R., Joseph T., Grigg M.E. \& Raverty S.A. 2016. Neospora caninum is the leading cause of bovine fetal loss in British Columbia. Vet. Parasit. 218(15):46-51.<http://dx.doi. org/10.1016/j.vetpar.2016.01.006> <PMid:26872927>

Zedda M.T., Rolesu S., Pau S., Rosati I., Ledda S., Satta G., Patta C. \& Masala G. 2010. Epidemiological study of Toxoplasma gondii infection in ovine breeding. Zoonoses Public Health 57(7/8):102-108. <http://dx.doi. org/10.1111/j.1863-2378.2009.01292.x><PMid:19968848> 